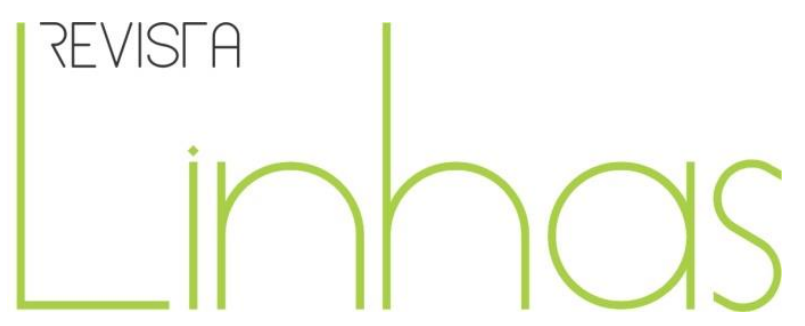

\title{
As rotinas: de hábitos estéreis a ações férteis
}

\begin{abstract}
Resumo
A jornada educativa das crianças pequenas (de 0 a 6 anos) é caracterizada por experiências que se repetem regularmente ao longo do tempo: lavar-se, comer, descansar... Chamamos esses momentos de rotina porque se repetem no tempo e na sua maneira de se desenvolver. As rotinas podem ser vividas como hábitos estéreis, mas também como ações férteis, como repetições simples ou como momentos de enriquecimento e cuidado. Neste segundo caso, com crianças mais velhas, é necessário repensar a organização das rotinas para ser - na pré-escola como na creche - uma experiência de enriquecimento pessoal e cidadania ativa.
\end{abstract}

Palavras-chave: Cotidiano. Educação Infantil. Cuidado. Cidadania Ativa.

\section{Para citar este artigo:}

STACCIOLI, Gianfranco. As rotinas: de hábitos estéreis a ações férteis. Revista Linhas. Florianópolis, v. 19, n. 40, p. 54-73, maio/ago. 2018. Título original: Le routine: da consuetudini sterili ad azioni fertili. Traduzido por Fernando Coelho, com revisão técnica de Catarina Moro.

\author{
Gianfranco Staccioli \\ Universidade de Florença - \\ Itália \\ gianfranco.staccioli@unifi.it
}




\title{
The routines: from dull habits to fertile gestures
}

\begin{abstract}
The day in early childhood education is given structure by certain experiences which repeat themselves regulary: washing one's hands, eating, resting... One calls these moments "routine". They may be lived as dull habits, but also as fertile gestures, as mere ripetition but also as enriching occasions of caregiving. We need to think about how best to organize our "routines" in order that, in nursery schools as well as in creches, they may be lived as personal enrichment and as active citizenship.
\end{abstract}

Keywords: Daily Life. Childhood Education. Care. Active Citizenship. 


\section{Repetições de sentido}

Os caminhos possíveis que permitem o crescimento são muitos. Há alguns promissores, outros cansativos, outros que são indispensáveis, outros que parecem agradáveis ou efervescentes. Quando uma pessoa encontra caminhos que são úteis para ela e quando esses caminhos também são compartilhados por quem vive com ela, comumente se diz que essa pessoa tomou hábitos bons ou maus. Tomar bons ou maus hábitos é um fato muito relacionado à cultura de pertença: comer no chão pode ser aceito, suportado, negado, exaltado, dependendo do contexto. Igualmente para outros atos que se repetem no cotidiano: lavar-se, dormir, descansar, ir ao banheiro... Pensar nos hábitos como bons ou maus comportamentos não nos ajuda. Talvez seja melhor pensar sobre os hábitos como a ações férteis ou hábitos estéreis.

As estradas dos caminhos habituais (em francês, route significa estrada; o termo rotina é derivado a partir daí) têm um duplo valor: por um lado, surgem de movimentos profundos, essenciais e necessários. Não se pode levar adiante sem elas, não se pode parar de comer, dormir ou desempenhar outras funções relacionadas ao bem-estar corporal e psíquico. Mas, como temos que exercitá-las com continuidade, elas correm o risco de se tornarem habituais, indispensáveis, rotinas estáticas; elas tendem a se tornarem hábitos e repetições quase automáticas. As rotinas, no pensamento comum, são muitas vezes consideradas o dejà vu da vida. Parece que não enriquecem, que não adicionam nada àquilo que já se conhece. Devem ser realizadas, executadas, repetidas num tempo estritamente necessário para realizá-las. Desta forma, aos hábitos são consuetudinários, mecânicos e até mesmo percebidos como chatos. Então, as rotinas tornam-se hábitos estéreis.

Sabemos que a chamada rotina para crianças não é um hábito estéril. Entre as duas tendências (a repetitiva e chata do hábito e a vital relacionada à descoberta do mundo) prevalece a que se baseia na curiosidade, que descobre uma repetição sempre diferente, ligada à maravilha do detalhe, à emoção do costume sem precedentes, à exploração do conhecido. Assim como acontece quando uma criança abre uma torneira no banheiro e a água cai na mão, mostrando-se com formas infinitas e imprevisíveis. As 
rotinas das crianças são mais frequentemente ações férteis, especialmente quando o contexto as reconhece e as valoriza. Para as crianças, a repetição é uma segurança também, é a maneira de parar o mundo agitado que flui diariamente com elas, é aquele rito criado pela raposa do Pequeno Príncipe que pede que ele volte no mesmo horário porque ela precisa saber, pois "se tu vens a qualquer momento, nunca saberei a hora de preparar o coração". A repetição combina na infância com segurança e riqueza, e ao mesmo tempo é sempre a mesma e sempre diferente. As rotinas tranquilizam e inovam ao mesmo tempo.

As rotinas das crianças são mais frequentemente ações férteis. Aquelas dos adultos são mais frequentemente hábitos estéreis. As rotinas das crianças não se repetem, porque em muitas delas os pequenos sempre podem encontrar algo novo, diferente, inexplorado. Neste sentido, falar de rotina ao se referir a crianças é uma contradição. Sendo as ações do cotidiano, sempre diferentes entre elas, comer, descansar, lavar-se não são rotina no senso comum do termo. Nós, adultos, precisamos fazer muito esforço para rever a repetição diária das ações usuais. E, igual esforço temos de fazer para fazer férteis muitas outras ações diárias também, como as atividades ao ar livre, aquelas no jardim ou aquelas que, nas primeiras instituições educacionais, eram chamadas de "brincadeira livre". Como se pode entender, a brincadeira livre não existe. Uma criança completamente espontânea não existe. Uma criança e sua brincadeira são sempre condicionados pelo contexto, pelas modas, pelas condições culturais do momento. Quando as crianças na infância jogam sozinhas (mesmo que estejam próximas uma da outra) com seus smartphones, pode se dizer que estão praticando uma "brincadeira livre"? Ou elas estão agindo fortemente direcionadas pelos modelos econômicos culturais? A brincadeira das crianças, a que não é dirigida pelos adultos, sempre representa o mundo dos mais velhos, com seus hábitos, modas, valores, expectativas que o distinguem. Um hábito fértil dedicado ao tempo da brincadeira ao ar livre deve ser plenamente entendido como rotina.

A validade da ideia pedagógica para colocar as rotinas na faixa etária de 0 a 3 anos é conhecida. Há anos, há uma extensa literatura sobre isso. As creches italianas desenvolveram uma sensibilidade particular no tema, com foco nos aspectos individuais 
de cada rotina (veja a bibliografia de referência também). Este tema é muito menos sentido na faixa etária de 3 a 6 anos, mas haveria muito a dizer ao se referir às crianças mais velhas também (STACCIOLi, 1997). As rotinas oferecem às crianças pequenas (de 0 a 3 anos) um ponto de apoio seguro e favorecem a organização equilibrada do tempo e do espaço. Elas oferecem uma acomodação coerente do antes e do depois, permitem prever o que acontecerá e organizar em conformidade; são uma experiência comunitária e transmissível aos pares e aos adultos; permitem um contato concreto com crianças de diferentes culturas; favorecem a narração e o compartilhamento... As rotinas também representam o lugar das novas aquisições cognitivas: "rotinas, rituais, regras resumem formas convencionais de conhecimento que as crianças aprendem e onde elas podem se orientar culturalmente" (CATARSI, FRESCHI, 2013, p. 26).

Os rituais (a partir da ambientação) favorecem um processo de integração serena: entrar, despir-se, encontrar o próprio adulto, aproximar-se de outras crianças, cumprimentar a mãe ou o avô, são atos que permitem não só uma reafirmação psíquica, mas uma estabilização do espaço temporal, relacional e afetivo também. Quando as crianças estão aptas a entender como se passa o dia na creche - e aqui os temas do ritmo, da lentidão e da calma também entram em jogo - tornam-se mais responsáveis, mais conscientes, mais autônomas. Não há muito para se concentrar nas características educacionais das rotinas. As creches na Itália e na Europa fizeram disso um emblema e um sinal de reconhecimento pedagógico. De qualquer forma, devemos pensar sobre como esses sinais vêm sendo (ou podem vir a ser) usados e desenvolvidos na pré-escola. E aqui o discurso se estende...

A pré-escola italiana conquistou - desde a década de 1970 (PESCIOLI, 1972) - o direito de ser considerada uma "primeira escola". Um direito que se tornou comum para muitos e permitiu cobrir com a escolaridade mais de $90 \%$ das crianças. Um direito que surgiu com propostas didáticas não casuais, organizadas e guiadas (também expressas nas Diretrizes emitidas na Itália em nível nacional em 2012). Um direito que buscou continuidade com a próxima escola (a escola primária, que começa aos seis anos, na Itália). Aos cinco anos, em todas as turmas da pré-escola, pensa-se em escrita, leitura e cálculo. Em formas discretas ou esquemáticas (com fichas específicas de aprendizado), 
ou seguindo abordagens baseadas no conhecimento. Cada professor tem certeza de que o que será aprendido pelas crianças na pré-escola será desenvolvido na escola primária pelos professores que virão.

Se esse raciocínio - que é um procedimento correto em relação à continuidade escolar da aprendizagem - se aplica a dimensões relacionais, afetivas e cognitivas, as rotinas (como experimentadas na creche) também podem ter um significado diferente na pré-escola. Como as rotinas se desenvolvem na pré-escola? Pode-se dizer que, durante o período de 0 a 3 anos, todas as habilidades para a autonomia do cotidiano já foram alcançadas? Pode-se dizer que a atenção das crianças e seu interesse no cotidiano (com suas possíveis descobertas) desapareceram? O que comporta uma maior atenção do professor às rotinas? Como organizar, por exemplo, o almoço ou a prática para ir ao banheiro, como continuidade dos conhecimentos e das habilidades adquiridas na creche? Como organizar espaços, tempos, relacionamentos, para que haja um enriquecimento constante que produza aquelas ações férteis a que se mencionou? Vamos observar brevemente alguns momentos de rotina, como o almoço, os cuidados com o corpo, o descanso, adicionando uma rotina incomum (os espaços ao ar livre) que pensamos ser uma presença diária que nem sempre é valorizada e utilizada.

\section{Comer na escola}

O almoço presta-se facilmente a uma reflexão sobre a continuidade. Na creche, a sucessão de modalidades organizacionais e sociais para adquirir habilidades diferentes são muito claras. Nos três anos hipotéticos que uma criança pode passar na creche, a posição do corpo também muda continuamente (no colo, na cadeira alta, usando a cadeira com os braços, sobre uma cadeira pequena, com uma cadeira maior...), bem como muda a altura das mesas, muda a maneira de comer (alguém põe na boca ou come sozinha, com as mãos e com os talheres, com a faca com a ponta arredondada...), mudam as relações interpessoais (com o adulto de referência, com alguns coleguinhas, com um pequeno grupo), altera a contribuição que está sendo solicitada às crianças (antes elas são servidas, depois elas podem se servir sozinhas, depois ajudam a pôr na mesa os 
talheres, a louça, aprendem a pôr a mesa, tirar da mesa, reorganizar os pratos sujos...). À medida que as crianças crescem, alteram as regras, altera a colocação na mesa, alteram os relacionamentos... (AA.VV, 2013).

Com os mesmos princípios de mudança e desenvolvimento, deve-se organizar o almoço na pré-escola. Se a dimensão amigável e relacional se intensificar, será necessário providenciar para que as crianças possam conversar calmamente com seus companheiros e também haverá maior autonomia no gerenciamento do tempo na mesa. Se a competência linguística estiver crescendo, será necessário favorecer as conversas, favorecendo a intimidade relacional entre pessoas que se conhecem e que comem juntas na mesma mesa. Se a dimensão de responsabilidade for aumentada, as tarefas das crianças também terão que mudar e tornar-se mais articuladas e autorresponsáveis, para que tudo funcione bem no almoço. Se a dimensão cultural se tornar mais complexa, há muito a fazer para retomar, aprimorar, expandir a "conversa" sobre alimentos, sua origem, sua qualidade ecológica, seus custos econômicos, seus efeitos no crescimento e no bem-estar pessoal.

As possibilidades organizacionais são muitas e muitas, e até mesmo diferentes entre si, foram experimentadas. Existem pré-escolas onde se usa uma distribuição de comida estilo "cantina” (um adulto que coloca comida nos pratos das crianças). Existem escolas nas quais se optou por utilizar a fórmula do autoatendimento e cada criança passa em frente ao pessoal da distribuição, pega a parte que lhe convém e vai sentar-se em um lugar da mesa. Existem escolas nas quais os alimentos são colocados em bandejas que contêm a quantidade apropriada para um grupo pequeno e o alimento é distribuído à mesa por uma criança do grupo. Existem escolas onde os adultos não comem com as crianças, ou comem em uma mesa separada, ou comem com um grupo de crianças. Em alguns casos, as crianças comem com o mesmo grupo; em outros casos, sentam-se livremente; em outros casos ainda, estão juntas em longas mesas... Esta é uma gama infinita de possibilidades e variações que precisam ser pensadas e calibradas, porque a escolha de uma ou outra não tem o mesmo valor e não transmite as mesmas mensagens. Sempre há uma questão (e nesta está o profissionalismo das educadoras e dos educadores): qual é a melhor forma e quais são as modalidades organizacionais mais 
eficazes para desenvolver um crescimento contínuo das crianças, tanto na autonomia (responsabilidade social), tanto no nível relacional (consciência afetiva) quanto no nível cognitivo (consciência comunicativa e reflexiva)?

Verifica-se que, nessas curtas notas sobre o almoço, não foi mencionado o aspecto nutricional. O que se come é importante também, como é importante cozinhar para que a comida seja boa e bem apresentada. $\mathrm{O}$ ato de nutrir-se (ou com os muito pequenos, ser nutridos) não só afeta aspectos fisiológicos e de apetite. Come-se melhor quando o contexto faz se sentir bem, quando há afinação emocional e relacional com os adultos e com seus colegas. A comida, além das calorias, é um ótimo veículo de vibrações que alimenta o corpo de emoções e afeições. A arte de dar de comer é propriedade daqueles adultos que estão conscientes de quanto entrelaçamento há entre a comida e a psique, entre a fome física e o relacionamento com os outros, entre hábitos consuetudinários e alimentos não conhecidos. O momento de comer torna-se uma ação diária fértil e agradável tanto para a criança quanto para o adulto que está com ela e com os colegas que estão à mesa com ela. E à medida que as crianças crescem, o momento da refeição se torna uma academia para exercer uma autonomia autossustentada pelo prazer.

A qualidade, a estética e os relacionamentos favorecem o prazer de comer. $\mathrm{O}$ espaço onde se come, como é decorado, como as crianças estão agrupadas, como as jarras de água ou os panos estão dispostos para qualquer necessidade... são todos elementos que afetam os relacionamentos e o bem-estar do convívio. "O espaço expressa valores, pensamentos, tem uma sua linguagem silenciosa, mas poderosa" (GALARDINI, 2003, p. 49). A organização espacial também inclui o tamanho do mobiliário, o dos talheres, o tipo de toalha de mesa a colocar, a escolha da mesa e das cadeiras para sentar, a predisposição das condições colaborativas para arrumar a mesa, a colocação das educadoras e da equipe. Há certamente razões nutricionais a ter em mente, bem como há razões econômicas que se entrelaçam com a alimentação na escola (na Itália, prefere-se alimentos "quilômetro zero", ou seja, produtos saudáveis e com cultivo orgânico). Igualmente importantes são as condições de trabalho das pessoas que consomem alimentos: um clima tranquilo na cozinha e boas relações entre prestadores de serviços e educadores tornam o almoço mais agradável e funcional. A dimensão educacional não 
para na organização de espaços, nas relações adulto/criança, mas deve afetar a organização da escola e sua relação com a sociedade em geral.

\section{Cuidados com o corpo}

O mesmo raciocínio pode ser feito para os momentos de ir ao banheiro também: acompanhados, sozinhos, usando e cuidando das coisas pessoais e comuns, estimulando experimentos em um pequeno grupo autônomo na pia, organizando supervisões pelas crianças, para que tudo esteja sempre em ordem e à disposição, favorecendo pequenas experiências científicas com a água, refletindo sobre como a água chega à escola... $\mathrm{Na}$ creche, as crianças pequenas devem ter apoio e ser encorajadas a se tornarem autonomamente independentes. A relação adulto/criança passa pela relação em dupla no fraldário, para uma relação mais independente com as necessidades corporais (da capacidade de reconhecer quando é o momento certo para fazer suas próprias necessidades, a capacidade de usar a escadinha para chegar ao fraldário, ao deslocamento para ir ao banheiro...). As funções que com os pequeninos competem ao adulto (esta rotina pluricotidiana é muitas vezes denominada como "a troca"), em seguida, passam às crianças: escalar a escadinha do fraldário, ir ao banheiro acompanhada ou sozinha, usar o papel higiênico, lavar-se com o sabão, abrir e fechar a torneira da água, secar-se... Esta é uma infinidade de conhecimentos executados que são indispensáveis para garantir o bem-estar físico, mas também a serenidade do próprio corpo. Os momentos da "troca", do banho e do cuidado físico com o corpo são momentos delicados porque é nesses momentos/lugares que se fixam as bases para uma abordagem correta para a descoberta da especificidade corporal e da sexualidade. São momentos também em que o dualismo sujo/limpo que fascina e espanta a cada criança é expresso: a mensagem adulta dizendo "não se suje, o cocô está sujo, não toque..." é oposta à necessidade de descobrir, manipular, explorar, conhecer.

As crianças pequenas, inicialmente, imitam o adulto, depois o acompanham em ações de autocuidado, depois podem fazer sozinhas. "Ajude-me a fazer sozinho" é o bem conhecido slogan Montessori que também é aplicável neste caso. Há uma infinidade de 
ações que são necessárias em momentos de cuidados com o corpo e que exigem a mesma atenção dada ao almoço ou a outras rotinas. Quando as crianças são mais velhas, se tiveram uma boa experiência na creche, elas podem fazer muitas coisas por conta própria. O cuidado e a predisposição de ambientes, horários, materiais e ferramentas de cuidados pessoais não devem ser ausentes na pré-escola porque ir ao banheiro pode ser um exercício cotidiano de responsabilidade social. Não desperdiçar água, colocar a toalha pessoal no seu lugar, deixar o banheiro limpo, manter em ordem os objetos comuns ou a bolsinha de higiene pessoal, guardar as coisas no próprio armário, manter seguros os equipamentos e as ferramentas presentes no ambiente, são todos comportamentos que requerem maturação e conscientização.

É no uso do banheiro também que iniciam as necessidades estritamente pessoais e comunitárias. O banheiro precisa ser compartilhado, pois se compartilham os lugares e as coisas da vida cotidiana na família ou na sociedade. Sujar as paredes, deixar papel no chão, largar garrafas e muitos outros comportamentos que mostram algum tipo de descuido para as coisas de todos, talvez não tenham um impacto direto nas experiências infantis relativas ao banheiro, mas certamente se relacionam com o cuidado de si e dos outros, para ter atenção para o pessoal e o comunitário, relacionam-se com o respeito pelos outros e com a responsabilidade pessoal. Todas as coisas podem ser ações férteis com as crianças na primeira escola quando suas vidas diárias são atravessadas - para usar uma locução não só italiana - por uma experiência de cidadania ativa.

Estamos, como se vê, muito longe do significado "médico" de um corpo que deve ser protegido para que não fique doente ou para que não doa (dois aspectos certamente que não devem ser negligenciados). O cuidado com o corpo refere-se ao fato de que adultos e crianças devem ser ensinados a cuidar de si mesmos e dos outros, ter solicitude para suas próprias necessidades e dos outros, viver a motricidade com prazer sem esforço competitivo. O corpo cuidado a respeito de si mesmo deve aprender a se conhecer, e o conhecimento do corpo (físico e psíquico) é um caminho que não acaba na vida. O corpo de cada criança é cuidado também no confronto com, em relação aos outros, a fim de desenvolver seu potencial colaborativo em vez de antagonista ou agressivo. Para fazer isso, não há necessidade de curar um corpo, mas precisa 
acompanhar aqueles corpos que tendem a se estragar, a sucumbir ou pedir demais por causa de sua própria cultura de pertença. Essas tendências aparecem cada vez mais frequentemente à medida que as crianças crescem e exigem, por parte dos adultos, intervenção intencional e consciente nas práticas diárias de cuidados.

Um discurso similar poderia ser feito para outros momentos da vida diária. As rotinas como um todo - mesmo do ponto de vista da quantidade de tempo que ocupam na creche ou na pré-escola - representam a dimensão mais ampla de viver na escola. Elas podem ser vividas como chatas ou simplesmente como ações inúteis a serem realizadas. Ou podem se tornar uma academia de cidadania. Nenhum outro ensinamento é praticado com a mesma quantidade de tempo que as rotinas, no seu todo, requerem. Estes são momentos pessoais e sociais que marcam a passagem de horas e dias que criam hábitos que moldam comportamentos que sustentam a consciência de que individualidade e sociabilidade são dois polos que podem e devem conviver integrando-se. Em uma escola florentina pós-guerra ("Scuola Città Pestalozzi”), foi ensinado, através da experiência diária, a se tornar "cidadãos livres". As crianças das primeiras turmas assumiram as tarefas e as responsabilidades (com o olho atento dos educadores da escola) que normalmente eram executadas por adultos (da recepção ao portão da escola, à ajuda na cozinha, aos cuidados com o jardim, à avaliação dos comportamentos inadequados dos colegas). Havia cidadãos desde criança, na "Scuola-Città", mas para se tornarem “cidadãos livres" havia um exercício diário que poderia durar anos. Democracia, liberdade, direitos e deveres estão em seu exercício diário. As rotinas representam um campo privilegiado para a educação social e a cidadania ativa.

\section{O descanso}

“As crianças não vêm à escola para dormir", disse uma dirigente escolar a uma mãe que perguntou por que sua criança, que na creche descansava à tarde, não podia mais fazer isso na pré-escola. A opinião dessa dirigente ainda está muito difundida. Muitos professores e pais ainda pensam que a escola é feita para trabalhar, para aprender, para estudar. O tempo de sono para eles parece ser tempo desperdiçado 
porque parece que nada contribui para a aprendizagem, aliás, parece que tira espaço das outras atividades (laboratoriais ou específicas) que são consideradas mais importantes. 0 sono seria um vácuo na programação, uma pausa improdutiva. Seria melhor reduzi-lo ou aboli-lo completamente. A essas considerações negativas, a respeito do descanso das crianças, são adicionadas outras de caráter mais organizativo: as pré-escolas não estão adequadamente equipadas para ter "salas de dormir" ou ambientes especificamente projetados para permanecerem em silêncio, lendo ou ficar em silêncio.

Ao afirmar que as crianças na pré-escola precisam descansar, vai um pouco contracorrente. Porque também o descanso não é considerado "educativo" nem mesmo nas famílias. Muitas vezes, as crianças o vivem de maneira não regulamentada, elas vão dormir tarde, adormecem com o smartphone na mão, permanecem com ele até que elas se cansem ou até cair no sono. Muitos pais se queixam de que as crianças com eles são inquietas, nervosas e instáveis. As professoras confirmam que esse comportamento também ocorre na escola. As crianças passam rapidamente de um interesse para outro, são instáveis, nervosas com seus coleguinhas. Ou, ao contrário, são lerdas, fracas, adormecem na carteira de escola. Mas sabemos que este é um círculo vicioso: quanto mais as crianças estão cansadas, quanto mais se agitam, mais elas ficam agitadas, menos conseguem descansar. Até o seu desmoronamento, onde quer que estejam. E também sabemos que existe uma correlação entre cansaço e aprendizagem. Se está feliz, aprende mais e melhor. A velocidade da informação que recebemos todos os dias não produz velocidade de aprendizado. Aliás, deixam o pensamento fugir de si mesmo. Para reverter a tendência da pressa (em casa, como na escola), precisaria estar fortemente convencido de que a calma, a Slow School (RITSCHER, 2015), o ritmo lento (ZAVALLONI, 2009), são um valor perdido que precisa ser recuperado para viver melhor (HONORÉ, 2014). A escola pode contribuir para o bem-estar e a formação de uma cultura pessoal sólida, apenas aceitando a regra de fazer menos para refletir mais. Se estivéssemos convencidos disso, não seria impossível convencer as famílias também e ajudá-las a diminuir a velocidade até mesmo com seus filhos.

O descanso das crianças com até três anos de idade é normal que seja predisposto com uma atenção ao tempo, espaço, condições de relacionamento, porque suas 
necessidades fisiológicas são muito mais evidentes e não podem ser negligenciadas. Os pequeninos adormecem em qualquer lugar, onde quer que sintam a necessidade. Os mais velhos podem "restringir" o repouso, mas com a consequência de se tornarem mais excitados e inquietos. Se fosse aceito o foco da lentidão, deveria se reconsiderar a organização da pré-escola para que se consintam momentos de descanso mesmo para crianças de cinco anos. Pode ser que os mais velhos não durmam, mas é importante dar pelo menos uma oportunidade diária programada para relaxar, permanecer em silêncio, ficar consigo mesmo. O quarto de dormir pode tornar-se o espaço do silêncio, o espaço da intimidade, o espaço da tranquilidade.

Estar na escola envolve fadiga, mesmo do ponto de vista acústico e relacional. Sempre há barulho, sempre há convivência, existem estímulos contínuos. O silêncio e a calma são igualmente importantes, e eles não encontram muito espaço hoje. Maria Montessori havia "inventado" a "lição de silêncio" e observou que "as crianças se interessam pelo silêncio; parece que elas experimentem uma espécie de encantamento; pode-se dizer que eles são raptados na meditação" (MONTESSORI, 1970, p. 49). Essas palavras foram escritas faz um século, para crianças que não conheciam o ritmo agitado e os estímulos tecnológicos e ambientais das crianças de hoje. Hoje, fazem refletir ainda mais, mesmo para aquela palavra, "meditação”, usada pela Montessori, uma palavra que, se tomada em sentido laico, nos lembra a importância da calma, de momentos íntimos de reflexão e pensamento, de silêncio exterior e interior.

"O descanso é um rito reconfortante, para ser apreciado com prazer, não deve ser uma imposição forçada e ligeiramente punitiva. Apesar de alguns problemas lógicos reais (como, por exemplo, a falta de um ambiente ad hoc), precisa evitar que o lugar de descanso se torne um "campo de pessoas deslocadas". O descanso deve ser tratado com dignidade, cuidando nos detalhes todos os aspectos práticos (iluminação, mobiliário, tempo...). Cada criança deve ter uma bolsa personalizada com o necessário para o descanso, (travesseirinho, roupa de cama ou um saco de dormir leve e facilmente lavável). As bolsas devem ser colocadas em um local fixo, acessível às crianças..." (RITSCHER, STACCIOLI, 2005, p. 90). Para ter a continuidade creche-pré-escola, precisamos reconsiderar o descanso e sua importância no nosso tempo apressado. É 
necessário dar a estes momentos aquela dignidade pedagógica que merecem (como acontece na creche). Estes são momentos que devem ser pensados nos detalhes também, porque o cuidado nas coisas e ambientes também são elementos indispensáveis para dar sentido ao descanso, na creche como na pré-escola.

\section{Os espaços externos}

O uso diário de espaços externos é outro tema relacionado às rotinas. Aqui, o discurso se torna mais complexo, não tanto por razões pedagógicas, quanto por hábitos culturais que atravessam a escola e as famílias. A creche ou a escola é frequentemente identificada com o prédio escolar. As paredes protegem, isolam, permitem recolhimento, comunhão, controle... Sabendo que seu filho está na sala de aula, sob o olho atento de um adulto, todos os pais ficam tranquilos. E também torna sereno qualquer educador que, em um ambiente controlado, consegue "manter ocupado sob vigia" a situação de um grupo de crianças. O controle do grupo ou da turma é importante porque, se as crianças permanecem abandonadas, elas podem acabar como as crianças de $O$ senhor das moscas (1980) de William Golding. Golding, em reação a uma grande quantidade de literatura infantil na década de 1950 (que representava as crianças sempre boas, justas, inocentes, alegres e com bom senso) conta uma história em que os meninos se tornam “maus, cruéis, viciosos, sujos e incapazes de viver juntos" (p. 6). Golding nos diz que o contexto é crucial para o comportamento de um grupo.

Construir um ambiente seguro e desafiador é importante na organização de espaços ao ar livre. A experiência e a vida de uma criança (ou de um adulto) não são completas se a educação escolar for sempre em sala de aula ou em laboratórios, sob o constante "controle" comportamental e cognitivo pelos adultos. Uma criança em crescimento também precisa de espaços onde possa haver autonomia, de movimento e agrupamento também. Nas creches italianas, ainda hoje, se sai pouco das salas de aula: nas pré-escolas, quase que exclusivamente nos intervalos. O espaço externo é uma rotina para reconsiderar e reorganizar. É verdade que, nos últimos anos, há um crescente 
interesse neste tópico (como no Outdoor Education ou na Educação Ativa ao ar livre), mas ainda há muito a ser feito (RITSCHER, STACCIOLI, 2005).

Mesmo em atividades ao ar livre, há necessidades de gerenciamento do contexto que precisam ser administradas, com o mesmo cuidado de rotinas “clássicas”. As regras são as mesmas: favorecer atividades de pequeno, ou muito pequeno, grupo; preparar o ambiente para que haja os materiais ou estímulos necessários (como quando se pensa nos objetos, condições, relacionamentos no momento do almoço ou do sono). Certificarse de que a coordenação de pequenos projetos ou iniciativas levem a uma responsabilidade predominante das crianças. Tomar cuidado para que essas iniciativas permitam "riscos", mas não determinem perigos. Isso significa que a posição do adulto também deve ser reconsiderada e revista.

Existe um elemento particular das atividades ao ar livre que deve ser considerado. Junto com a preocupação de "perder o controle" das crianças, há uma resistência implícita ou explícita que frequentemente envolve pais e educadores: lá fora está frio ou está chovendo e, portanto, a saúde física parece estar em perigo (e então não se pode sair); as crianças podem se machucar com madeiras ou árvores (e então as árvores podem ser removidas ou enroladas com espuma para evitar acidentes); as caixas de areia e os jogos com a terra são anti-higiênicos e levam a doenças (e, em seguida, o jardim é transformado em um espaço completamente pavimentado); plantas, flores ou arbustos podem ser venenosos (e, em seguida, gramas artificiais são colocadas). Essas resistências são mesmo compreensíveis, mas ao invés de agir para removê-las e condicionar o espaço, às vezes são usadas como limites inadmissíveis. O exterior não é um campo minado. $O$ exterior pode se tornar uma rotina fascinante se se consideram esses aspectos e se for possível lidar com isso para destacar as valências positivas e específicas que lembramos estar presentes nas rotinas tradicionais.

Tornar diária a educação ao ar livre é um passo muito importante. Sair durante o ano todo, mesmo quando as condições climáticas ou a temperatura não estão na norma, é um passo ainda maior. Sair e considerar o espaço ao ar livre como um lugar a ser tratado como outras rotinas é outro salto de qualidade que ainda não foi assimilado e compreendido pelas famílias ou educadoras. A organização dos espaços ao ar livre das 
pré-escolas muitas vezes responde a uma lógica de escape (um espaço aberto e vazio para correr, de modo a descarregar as energias comprimidas dentro da sala de aula) ou de lazer (com equipamentos que recordam jardins públicos ou parques de diversões, para aliviar o trabalho árduo do trabalho "sério"). Um jardim que se torna rotina, rico em ações férteis, transforma o ficar ao ar livre em um “ambiente de aprendizagem”, uma fonte de estímulos e possibilidades: "o que uma criança pode aprender ficando fora, por exemplo, no jardim da escola, jogando, explorando, reagindo às solicitações sensoriais e aos estímulos que recebe, é o ambiente de aprendizagem mais formidável que a infância pode ter, irredutível a qualquer 'ambiente de aprendizagem' interno, embora bem organizado e gerenciado" (FARNÉ, 2014, p. 257).

A inserção de espaços externos, assim entendidos, na cesta educacional das rotinas, facilita, por um lado, o aprimoramento das tradicionais (comer, dormir, etc. também podem ser predispostas e utilizadas como “espaços de aprendizagem”) e, por outro lado, facilita a superação das resistências (relacionadas à saúde física ou à segurança) que ainda são generalizadas, em muitos adultos também.

\section{As rotinas informais}

As rotinas diárias são, em nossa opinião, tanto as classificadas como tais, como as que podem se tornar (como sair diariamente da sala de aula), e como aquelas que não têm uma forma predeterminada, mas são repetidas todos os dias, várias vezes. Estas últimas devem ser chamadas de "rotinas informais", porque elas são mais imateriais do que as outras, mas também exigem predisposição, atitude de escuta, suporte de autonomia, intervenção de ajuda, nem mais nem menos do que as outras rotinas.

Em qualquer momento da jornada educativa, podem ocorrer eventos imprevistos. Como todos sabemos, a vida não é totalmente programável. Como Cusano (De ludus globi, 1463) ensinava seus estudantes de filosofia, pode-se jogar uma bola cortada ao meio, pensando que ela possa ir reto, mas a bola, como as ações que fazemos na vida, estará sujeita à contingência, sorte e acaso. O percurso da bola é comparável ao curso da vida (cheio de imprevistos e acidentes), bem como nas programações escolares, lançadas 
como uma bola cortada no meio, não é dito que produza o esperado. Aliás, muitas vezes é o inesperado que aparece, e essa sua quase imparável recorrência o faz, em alguns aspectos, próximo das rotinas. Lidar com isso (o que, obviamente, não significa deixar-se levar pela casualidade e pelo inesperado) é uma modalidade de ensino que abandona as programações rígidas e verificáveis. O inesperado é aquela força (como nos lembra Eurípides) que é impulsionada pela força sobre-humana ("o esperado não é cumprido e um deus abre a porta ao inesperado"). Isto é, o inesperado não só não pode ser evitado, mas deve ser sustentado. Em vez de aguardar o esperado pelas crianças que vivem na escola todos os dias, seria necessário estar preparados para o inesperado. E, se necessário, usá-lo.

Luca e Gianni têm cinco anos de idade, estão no jardim, perto de uma tília. A tília projeta a própria sombra no chão, parte na parede da escola. Em algum momento, eles fazem uma descoberta inesperada. "Olhe, professora! Olhe! Agora a sombra se foi!" Gianni, primeiro, se posicionou para ter a sua sombra projetada na parede e depois, com um pulo, saltou para a área de sombra projetada a partir da tília. "Minha sombra foi comida pela grande sombra. Experimente você também! Coma a sua também! Você verá!”, diz Gianni. Luca, que participou de toda a cena, perguntou: “Professora, por que essa sombra come nossas sombras?" Como responder a essa pergunta? Certamente não com uma explicação científica.

O “jogo do inesperado" poderia continuar, por exemplo, "maravilhando-se" que nem sempre um mais um dá dois. No caso das duas sombras, um mais um dá um ainda. Uma sombra sobre outra sombra dá apenas uma sombra. Ou "maravilhando-se" que um objeto pequeno possa fazer uma sombra maior do que um objeto ainda maior, ou que uma sombra pode ser moldada e criar personagens ou animais... O inesperado, o informal, o ocasional, fazem parte do cotidiano, voltam continuamente, são sempre diferentes e requerem a mesma atitude, caso a caso, dia a dia, como fossem uma rotina. Como comer, dormir, brincar, cuidar do próprio corpo, a repetição da maravilha (repetir o irrepetível é uma boa contradição) é uma parte essencial da vida, uma atitude, um ato fértil que acompanha diariamente a vivência. 
Valorizar as rotinas, tendo uma posição de destaque no currículo do crescimento, também tem como objetivo permitir que as crianças vivam a escola, não apenas que permaneçam na escola. Não é fácil realizar uma escola onde as crianças estão bem porque sentem que há vida em todos os momentos. Há vida ao interceptar necessidades, desejos, histórias pessoais, das crianças e aquelas relacionadas ao conhecimento do mundo, como o mundo era antes, como será o futuro. As crianças têm uma curiosidade infinita pelo conhecimento, e especialmente quando viajam por estradas que são importantes para elas também.

As atividades de rotina até agora mencionadas reavaliam a importância de realizar experiências motivadoras e personalizadas que permitem o prazer de explorar e estimular a curiosidade. Atividades que dão às crianças a oportunidade de crescer de forma independente, testar-se diante de situações protegidas, enfrentar diferentes dimensões culturais, experimentar suas habilidades pessoais, olhar para além das propostas diretas e pré-organizadas pelos adultos.

Viver a escola e não na escola ainda significa perceber (por parte das crianças, mas também pelos adultos) que não há atividades de série $A$ e atividades de série $B$. Que não há momentos de trabalho e momentos de lazer. Que não há tempo livre, exceto o que é libertado dos preconceitos e costumes não refletidos. Que se aprende fazendo e experimentando, sustentados pela paixão e prazer emocionado. Que se cresce apenas medindo-se com o possível e o arriscado. Que se está melhor quando se pode agir e conversar de forma autônoma, em pares ou em um grupo pequeno. Que é bom quando os adultos dão segurança sem serem opressores quando conduzem à autonomia sem ceder ao abandono, quando fazem sentir a proximidade deles sem impor seus planos.

Viver a escola também é um grande exercício de democracia. Assumir a responsabilidade por suas ações, lidar com decisões que não oferecem certeza, compartilhar com grandes ou pequenas aspirações e curiosidades, educar-se para o "sentido da realidade" é a melhor maneira de aprender a avaliar e decidir com maior consciência. Estas e outras ainda são as regras para o que hoje se chama de cidadania ativa. Cidadãos conscientes que se tornam "livres" porque desde muito pequenos, no trabalho diário e rotineiro, aprenderam a lidar com eles mesmos, com os outros e com 
esse complicado mundo dos adultos e suas regras. As rotinas não são apenas uma incumbência necessária, mas oferecem a oportunidade de tornar a vida cotidiana interessante e enriquecedora. Pelo hoje e pelo amanhã.

\section{Referências}

AA.VV., A tavola si cresce, <http://www.mediatecatoscana.net/sociale.php>, 2013.

Boffo Vanna, La cura in pedagogia, Clueb, Bologna, 2006.

Bortolotti Alessandro, Schenetti Michela, Outdoor education: l'educazione attiva all'aperto, numero speciale di Bambini, n.4/5, Spaggiari Editori, Parma, 2015.

Catarsi Enzo (a cura di), Il sonno nel nido d'infanzia, Junior, Azzano San Paolo (Bergamo), 2008.

Catarsi Enzo, Freschi Enrica, Le attività di cura nel nido d'infanzia, Junior, Azzano San Paolo Bergamo, 2013.

Farné Roberto, Agostini Francesca. (a cura di), Outdoor Education., Edizioni Junior, Parma, 2014.

Galardini Anna Lia, Crescere al nido. Gli spazi, i tempi, le attività, le relazioni, Carocci, Roma 2003.

Golding William, Il signore delle mosche, Mondadori, Milano, 1980 (ed. or. Lord of the Files, 1954).

Goldshmied Elinor, Jackson Sonia, (1996) Persone da zero a tre anni. Crescere e lavorare nell'ambiente del nido, Junior, Bergamo (ed. or. People under Tree. Young Children in Day Care, Routledge, London,1994). 
Honoré Carl, Elogio alla lentezza. Rallentare per vivere meglio, BUR, Milano 2014, (ed. or. Praise of Slowness, 2004).

Honoré Carl, The Beauty of Slowing Down, ebook, 48 pages Published February 7th 2012 by Harper One.

Marchioli Giulia, Vigoni Simona, Vita quotidiana al nido. I contesti di cura, La Scuola, Brescia, 2007.

Montessori Maria, Manuale di pedagogia scientifica, Giunti, Firenze, 1970 (1912).

Mortari Luigina, La pratica dell’aver cura, Bruno Mondadori, Milano, 2006.

Muntoni Ludovica., I bambini pensano difficile. L'organizzazione delle idee nella scuola dell'infanzia, Carocci, Roma (2005).

Musi Elisabetta, Invisibili sapienze. Pratiche di cura al nido, Edizioni Junior-Spaggiari, Parma. 2011.

Pescioli Idana, La prima scuola, gli adulti all'opera con i bambini dai 3 ai 5 anni, Editori Riuniti, Roma, 1972.

Ritscher Penny, Slow School, Giunti, Firenze 2013.

Staccioli Gianfranco (con Ritscher Penny), Vivere a scuola. Programmare per situazioni, Carocci Editore, Roma, 2005.

Staccioli Gianfranco, Tra le righe, vivere volentieri la scuola di base, La Nuova Italia Editrice, Roma 1997.

Zavalloni Gianfranco, La pedagogia della lumaca, EMI, Bologna, 2009.

Agosto 2017. 